\title{
Piperine depresses the migration progression via downregulating the Akt/mTOR/MMP-9 signaling pathway in DU145 cells
}

\author{
YUAN ZENG and YING YANG \\ College of Life Sciences, Northwest University, Xi'an, Shaanxi 710069, P.R. China
}

Received November 5, 2017; Accepted February 8, 2018

DOI: $10.3892 / \mathrm{mmr} .2018 .8653$

\begin{abstract}
Piperine, an alkaloid derived from natural products, has been demonstrated to exert antitumor activities in vivo and in vitro. However, its anti-tumor effect has not yet been illustrated in the prostate cancer ( $\mathrm{PCa})$ metastatic process. Thus, the present study explored the influence of piperine on PCa and the underlying molecular mechanism. Cell migration was detected via the Transwell chamber model. Total protein was identified by western blot analysis. The data revealed that piperine markedly repressed cell proliferation and migration, and induced apoptosis in PCa DU145. In addition, LY294002, an protein kinase B (Akt) inhibitor, greatly suppressed the expression level of phospho (p)-Akt, matrix metalloproteinase (MMP)-9 and p-mammalian target of rapamycin (mTOR), suggesting that the activation of the Akt/mTOR/MMP-9 signaling pathway may participate in regulating cell migration in PCa. Furthermore, piperine reduced the expression of p-Akt, MMP-9 and p-mTOR. Together, these data indicated that piperine may serve as a promising novel therapeutic agent to better overcome PCa metastasis.
\end{abstract}

\section{Introduction}

Prostate cancer ( $\mathrm{PCa})$, one of most common malignancy, is a severe health threatening illness for older men in the world (1). PCa primarily begins as being hormone dependent tumour, then it transforms into being hormone independent tumour and resists to hormone related therapy as the disease advances (2). Currently, several treatment approaches are accessible for PC patients, including surgery, radiation or androgen-deprivation therapy (3-6). However, it is necessary to discover novel agents to surmount several adverse effects related with present therapies.

Natural products, derived from plants or microbes, have developed a crucial resource of anti-cancer treatments. Piperine, one of the most popular spices used in food and in traditional

Correspondence to: Professor Yuan Zeng, College of Life Sciences, Northwest University, 229 Taibai North Road, Xi'an, Shaanxi 710069, P.R. China

E-mail: zengyuansxxa@126.com

Key words: piperine, matrix metalloproteinase 9, DU145, protein kinase $\mathrm{B} /$ mammalian target of rapamycin, migration
Chinese medicine, is a chief plant alkaloid present in long and black peppers (Piper nigrum Linn and Piper longum Linn). It has been broadly informed that piperine has an extensive pharmacological properties, such as antioxidant (7), anti-inflammatory $(8,9)$, hepatoprotective $(10)$, antimicrobial $(11,12)$, immunomodulatory and anticancer activities $(13,14)$. In spite of its broad use and its tendency to reduce the chances of several cancer types, the valuable effects of piperine against $\mathrm{PCa}$ are poorly understood. Thus, there is great interest in recognizing therapeutic effect in the treatment of $\mathrm{PCa}$.

Though there is plenty of data for cancer preventative and therapeutic effects, the impact of piperine on PCa cell migration has not yet been fully explored, nor is the molecular mechanism of piperine-mediated prohibition of cancer cell migration obvious at this moment. In this work, we investigated the influence of piperine in prostate carcinoma cell migration, and the underlying mechanisms of piperine on cell migration. Our results indicated that piperine depressed the migration process via downregulating the protein kinase $\mathrm{B}$ (Akt)/mammalian target of rapamycin (mTOR)/matrix metalloproteinase (MMP)-9 signaling pathway in DU145 cells.

\section{Materials and methods}

Cell lines and cell culture. The androgen-independent PCa cell line (DU145) was purchased from the American Type Culture Collection (ATCC; Manassas, VA, USA). DU145 cells were cultured in DMEM medium (HyClone; GE Healthcare Life Sciences, Logan, UT, USA) added with 10\% FBS (Invitrogen, Victoria, Australia), $100 \mathrm{IU} / \mathrm{ml}$ penicillin and $100 \mu \mathrm{g} / \mathrm{ml}$ streptomycin (nvitrogen; Thermo Fisher Scientific, Inc., Waltham, MA, USA) and all cells were incubated at $37^{\circ} \mathrm{C}$ in a humidified incubator at $5 \% \mathrm{CO}_{2}$.

Cell viability assay. To explore the cell proliferation, we used the Cell Counting Kit-8 (CCK-8) (WST-8; Dojindo Molecular Technologies, Inc., Kumamoto, Japan). Cells ( $7 \times 10^{3}$ cells/well) were planted onto 96 -well plates and raised for $24 \mathrm{~h}$. Next cells were cultured with piperine for $48 \mathrm{~h}$, and subsequently CCK-8 solution $(10 \mu \mathrm{l})$ was added into the 96 -well plates. After $4 \mathrm{~h}$ of culture, the absorbance at $450 \mathrm{~nm}$ was read using a plate reader (Molecular Devices, Sunnyvale, CA, USA).

Flow cytometry analysis of apoptotic cells. DU145 cells were planted at a concentration of $1 \times 10^{6} / \mathrm{ml}$ onto 6 -well culture 

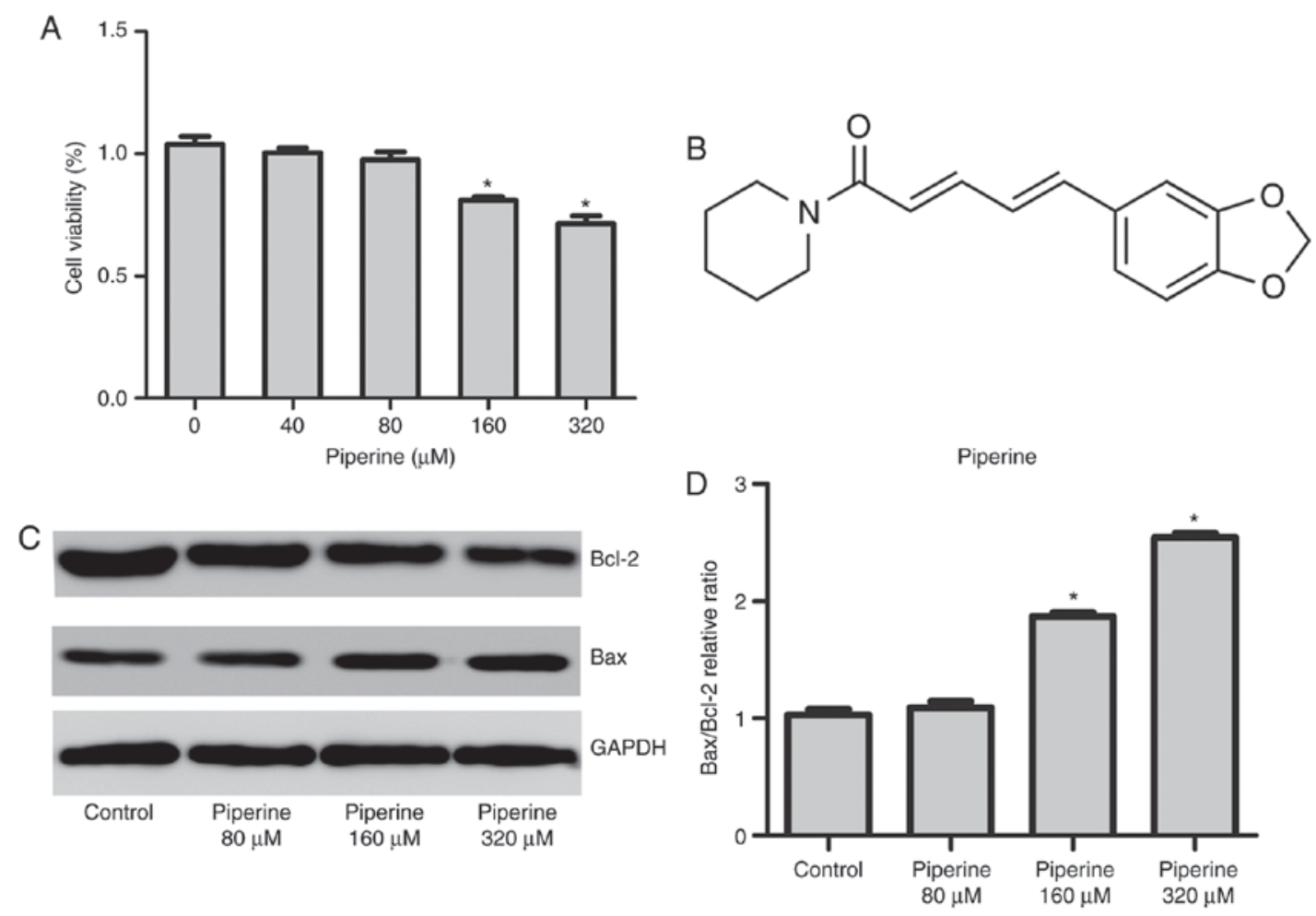

Figure 1. Piperine decreases cell proliferation and apoptosis in DU145 cells. DU145 cells were cultured with the indicated concentrations of piperine for $48 \mathrm{~h}$. (A) Cell viability was evaluated via Cell Counting kit-8 assay. Cells cultured in a medium without piperine were defined as the control. (B) Chemical structure of piperine. (C) Indicated protein levels of Bax and Bcl-2 were measured via western blotting. (D) Densitometric analysis was used to quantify the ratio of Bax/Bcl-2. The results are presented as the mean \pm standard deviation $(\mathrm{n}=3)$. " $\mathrm{P}<0.05$ vs. Control group. Bcl-2, B-cell lymphoma 2; Bax, Bcl-2-associated X protein.

plates. While the cells achieved about $70 \%$ degree confluence, the medium was exchanged, and piperine $(160 \mu \mathrm{M})$ or diluent was supplemented. Subsequently, DU145 cells were trypsinized to obtain a single cell suspension. One million cells were double-stained with APC-labeled annexin V and propidium iodide (BD Biosciences, Franklin Lakes, NJ, USA). Proportion of apoptotic cells was determined by flow cytometry (BD Biosciences).

Reverse transcription-quantitative polymerase chain reaction $(R T-q P C R)$. Total RNA was isolated from DU145 cells and then quantitated by an ultraviolet spectrophotometer. Next cDNA was synthesized from RNA (200 ng) in a $20 \mu 1$ reverse transcription reaction (Promega Corporation, Madison, WI, USA). qPCR was worked as follow: $30 \mathrm{sec}$ at $94^{\circ} \mathrm{C}$ for denaturation, $30 \mathrm{sec}$ at $54^{\circ} \mathrm{C}$ for annealing and $30 \mathrm{sec}$ at $65^{\circ} \mathrm{C}$ for extension, for a total of 30 cycles. qPCR was completed with the SYBR green real-time PCR kit (Qiagen, Hilden, Germany) and the ABI 7500 Sequence Detection System (Applied Biosystems; Thermo Fisher Scientific, Inc.). PCR products were run on $2 \%$ agarose gels to prove that correct molecular sizes were present. Each sample was analyzed in triplicate using RT-qPCR. The primers for RT-qPCR as follow: MMP-9, forward 5'-AATCTCTTCTAGAGACTGGGAAGGAG-3' and reverse 5'-AGCTGATTGACTAAAGTAGCTGGA-3'; GAPDH, forward 5'-AGAGAGAGGCCCTCAGTTGCT-3' and reverse 5'-TTGTGAGGGAGATGCTCAGTGT-3', synthesized by BGI Tech (Shenzhen Co., Ltd., Shenzhen, China). GAPDH was used as an internal control. Fold changes were analyzed using the $2^{-\Delta \Delta \mathrm{Cq}}$ method.
Western blotting. Total proteins were got by cell lysis in ice-cold RIPA buffer in DU145 cells. Cells extracts were subjected to a $10 \%$ polyacrylamide gel and blotted onto a polyvinylidene difluoride (PVDF). The blot was then blocked with $5 \%$ non-fat milk in TBST for $2 \mathrm{~h}$ and subsequently incubated at $4^{\circ} \mathrm{C}$ overnight with primary antibodies anti-MMP-9 $(1: 1,000)$, as well as p-Akt, t-Akt, p-mTOR, mTOR, Bcl-2, Bax, and anti-GAPDH (1:500), and then cultivated with goat anti-rabbit IgG-HRP. The bands were visualized via ECL Western blot detection reagents (Thermo Fisher Scientific, Inc.), and the results were analyzed by Quantity One (Bio-Rad Laboratories, Inc. Hercules, CA, USA) software.

Transwell migration assay. Trypsinized cells suspended in serum-free DMEM medium were planted onto upper chamber at a concentration of $5 \times 10^{5} /$ well, and $600 \mu 1$ of medium added with $10 \%$ serum were supplemented to the inferior chamber. After $48 \mathrm{~h}$, the cells were wiped off of the inserts with a cotton swab. $4 \%$ paraformaldehyde (PFA) was used to fix the residual cells migrating to the other side of the membrane. Then the cells were stained with Crystal Violet for $10 \mathrm{~min}$, and subsequently the mean amount of those cells was analyzed to assess their migrated ability. Images were captured with the Olympus microscope.

Statistical analysis. All quantitative data were performed as mean \pm SEM and one-way ANOVA followed by post-hoc Tukey's test to analyze the differences between sets of data. Statistics were completed using the SPSS 20.0 software (IBM Corp., Armonk, NY, USA). P $<0.05$ was considered to indicate a statistically significant difference. 
A

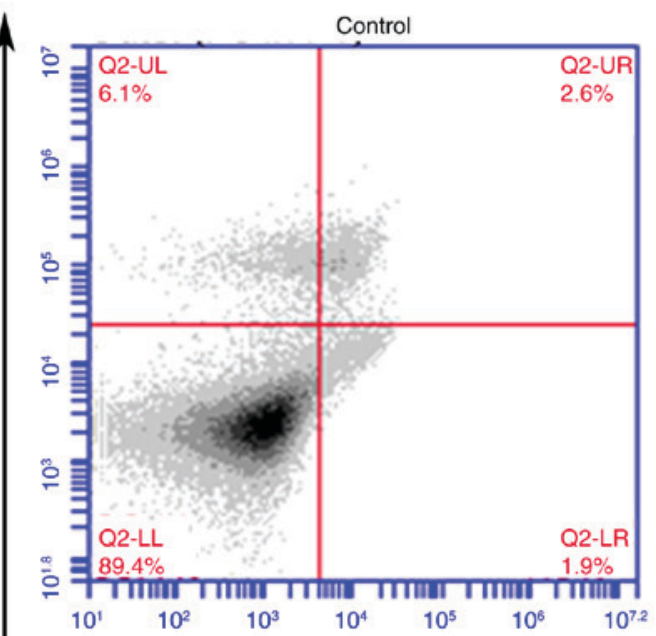

$\bar{a}$

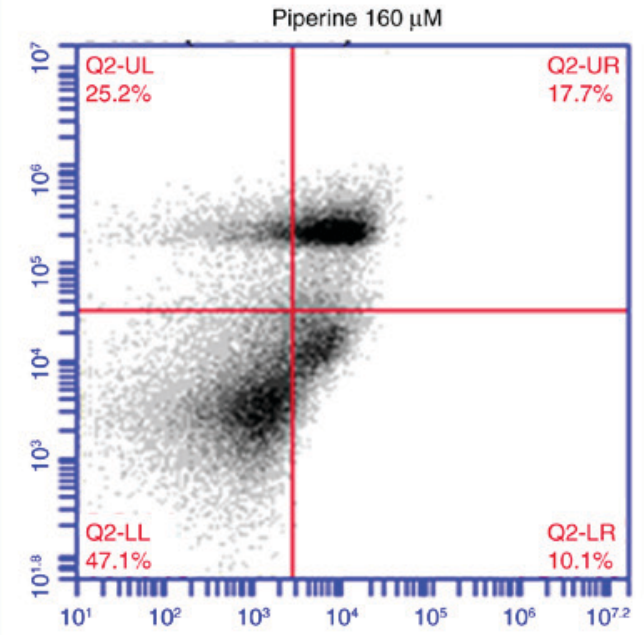

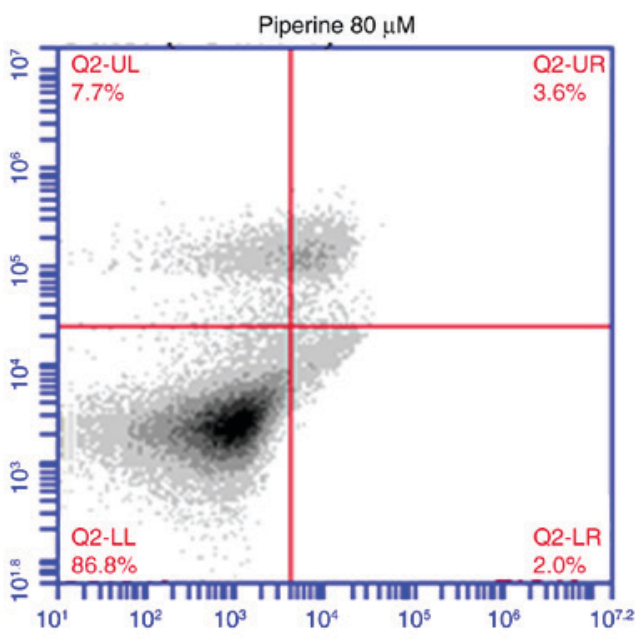

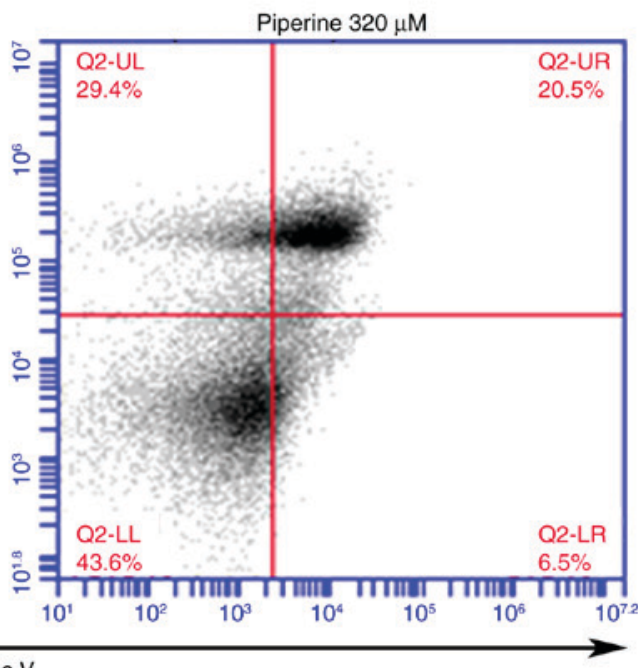

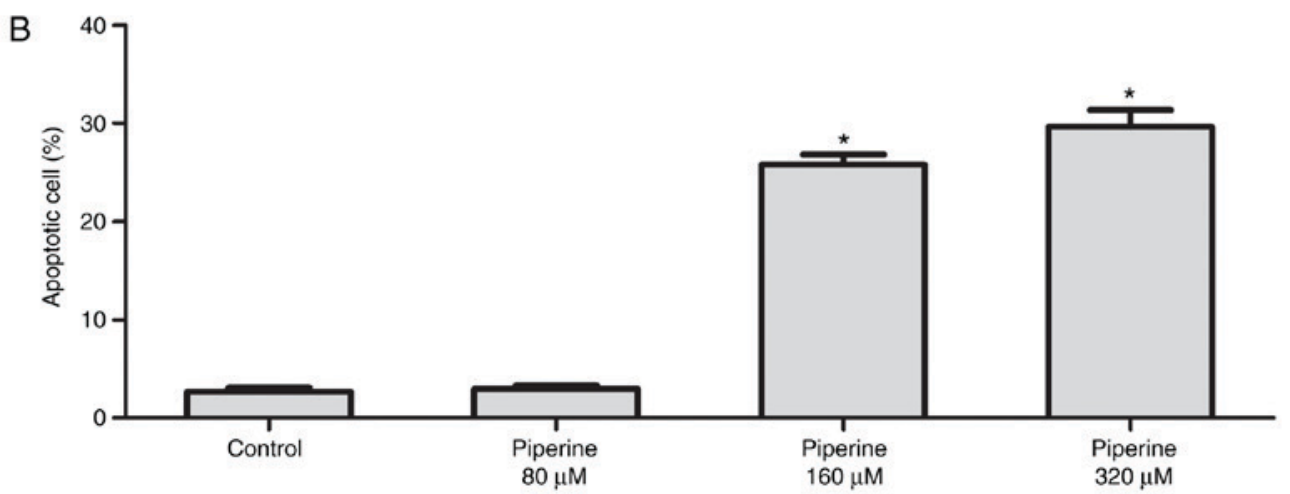

Figure 2. Effect of piperine on apoptosis in DU145 cells. DU145 cells were incubated with piperine ( 80,160 or $320 \mu$ M) for 48 h, and then the cells were processed for cell apoptosis analysis using FITC-Annexin V and PI double staining. (A) Representative flow cytometry images are presented and (B) the quantitative analysis of FITC-Annexin V positive cells is presented as the mean \pm standard error from 3 independent experiments. ${ }^{*}<0.05$ vs. Control group. FITC, fluorescein isothiocyanate; PI, propidium iodide.

\section{Results}

Piperine repressed cell proliferation and apoptosis in $\mathrm{PCa}$ DU145 cells. To explore the cytotoxic effects of piperine on human PCa cells, DU145 cells were pretreated with piperine for $48 \mathrm{~h}$, and subsequently examined the viability by the CCK-8 assay. The outcome was that piperine treatment remarkably diminished cell proliferation in a dose-dependent manner (Fig. 1A).
The chemical structure of piperine was showed as Fig. 1B. To uncover the role of piperine on cell proliferation and apoptosis, the western blotting and the Annexin V apoptosis detection kit was performed as previously reported (15). DU145 cells were pretreated with piperine $(80,160$ or $320 \mu \mathrm{M})$ for $48 \mathrm{~h}$ and subsequently stained with Annexin V and propidium iodide to visualize the cells numbers via fluorescent microscope. Besides, piperine treatment group reduced the expression of antiapoptotic protein $\mathrm{Bcl}-2$ and promoted the expression of 


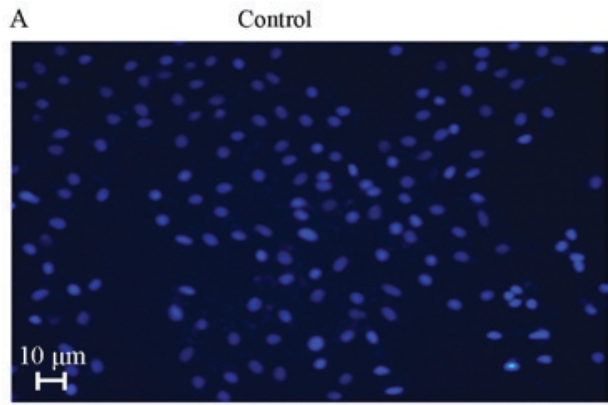

$\mathrm{B}$

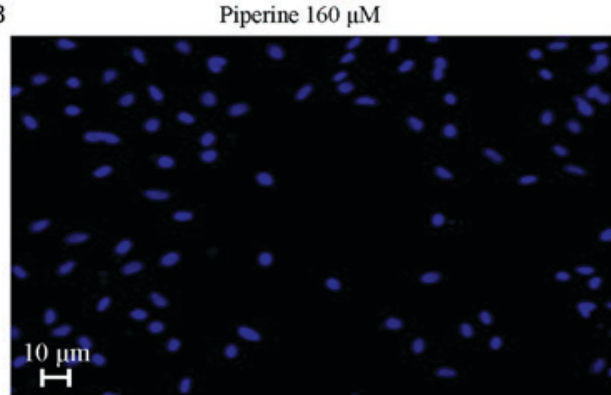

C

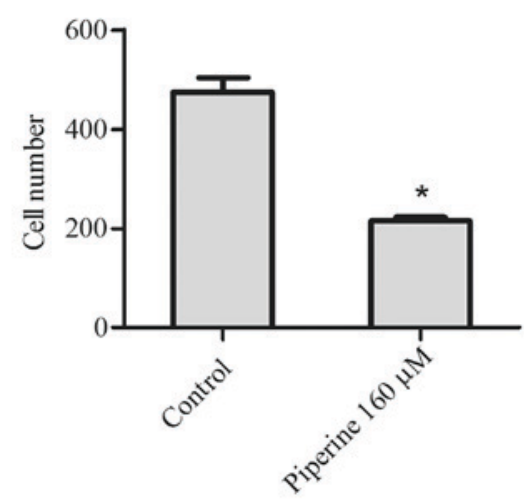

D

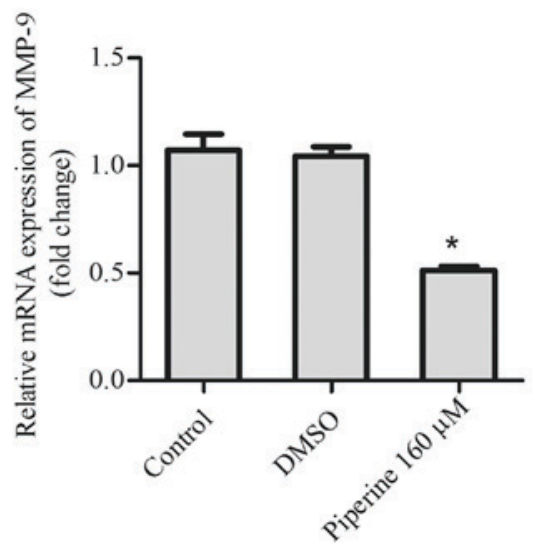

Figure 3. Piperine decreases cell migration in DU145 cells. Migration was performed via a Transwell assay. DU145 cells were pretreated with (A) control or (B) piperine $(160 \mu \mathrm{M})$ for $48 \mathrm{~h}$ (scale bars, $10 \mu \mathrm{m})$. (C) The cell number was calculated in 4 random fields for each treatment. (D) The expression level of MMP-9 in DU145 cells was performed via reverse transcription-quantitative polymerase chain reaction. GAPDH was used as the internal control. Data are presented as the mean \pm standard deviation $(n=3)$. ${ }^{*} \mathrm{P}<0.05$ vs. Control group. MMP-9, matrix metalloproteinase-9; DMSO, dimethylsulfoxide.

proapoptotic protein Bax (Fig. 1C and D). We observed that the apoptotic cells markedly increased in piperine treatment group compared to the control group (Fig. 2A and B). Based on the above results, we uncovered that piperine could promote cell apoptosis and hinder cell proliferation in DU145 cells in a dose-dependent manner, and the concentration $160 \mu \mathrm{M}$ was selected for further mechanistic studies.

Piperine reduced the migration of DU145 cells. To establish how piperine influences the metastatic processes, the role of piperine on DU145 cell migration was performed. In Transwell migration assay, piperine decreased cell migration significantly after $48 \mathrm{~h}$ in the DU145 cell (Fig. 3A-C). In agreement, results of western blot and qPCR disclosed that piperine could also suppress the expression of MMP-9 (Figs. 3D and 4A-B). These consequences indicated that piperine could inhibit the migration of DU145 cells.

Piperine inhibited DU145 cells migration via Akt/mTOR signaling pathway. Numerous reports indicate that Akt/mTOR signaling pathway perform a vital effect in regulating MMP-9 expression in DU145 cells (16). To recognize the influence of Akt/mTOR signaling pathway, western blotting was performed. We noticed that piperine pretreatment remarkably decreased the expression of phosphorylated mTOR (p-mTOR) and phosphorylated Akt (p-Akt) in DU145 cells (Fig. 4C-E). To further exam the effect of piperine in the DU145 cells metastasis process, LY294002, an Akt inhibitor, was chosen to combine with piperine for mechanism and functional research. In cells pretreatment with LY294002 and piperine group relative to the piperine alone group, cell migration was significantly reduced in the DU145 cells (Fig. 5), as well as the protein levels of p-mTOR, p-Akt, and MMP-9 (Fig. 6A-D). Collectively, these outcomes imply that Akt/mTOR signaling pathway was partially correlated to the anti-metastasis function of piperine.

\section{Discussion}

In our study, the involvement of piperine and its molecular mechanism in DU145 cells was investigated. Piperine was exhibited to promote apoptosis and to inhibit cell proliferation in DU145 cells as demonstrated by CCK8 and flow cytometry. At the molecular level, the results demonstrated that piperine suppressed Akt and mTOR activation. In addition, PI3K/Akt/mTOR was identified to be a vital molecular target of piperine $(16,17)$. Akt and mTOR invalidation, using inhibitor, reduced the MMP9 expression in DU145 tumor cells. Collectively, these data suggested that piperine may be beneficial in the treatment of PCa.

Currently, it is thought that piperine could present as a natural source anticancer drug due to its reported capability to repress carcinogenesis, angiogenesis, metastasis, and tumor growth (18-20); nonetheless, the impact of piperine on human PCa cells has not completely been understood. Ouyang et al showed that piperine represses the proliferation of human $\mathrm{PCa}$ cells through promotion of autophagy and cell cycle arrest (21). A recent study displays that piperine treatment significantly diminished Prostate Specific Antigen (PSA) levels in LNCaP cells, also promoted apoptosis in hormone dependent $\mathrm{PCa}$ 

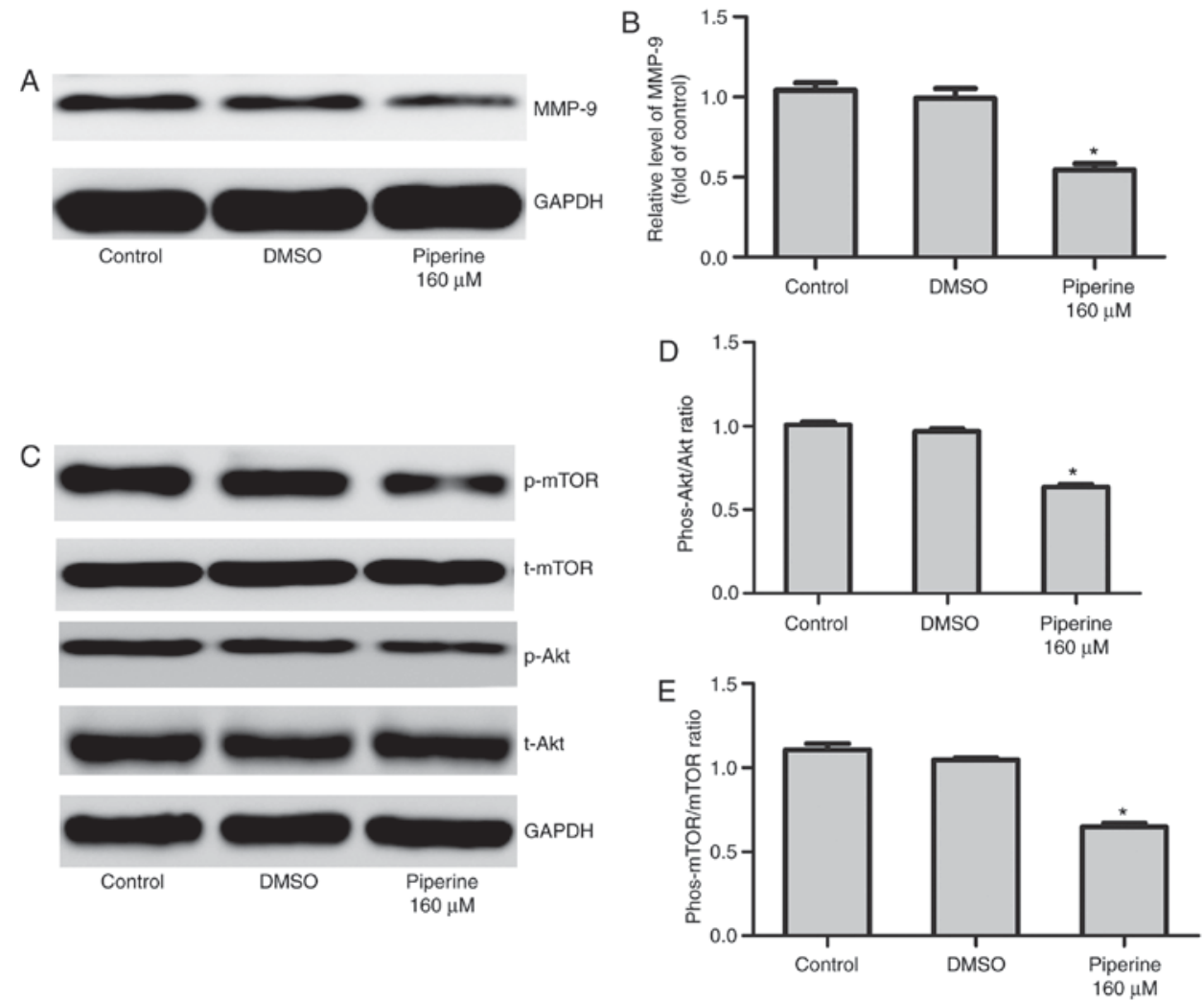

Figure 4. Piperine significantly decreases p-AKT, p-mTOR and MMP-9 expression in DU145 cells. Cells were cultured with piperine (160 $\mu \mathrm{M})$ for $48 \mathrm{~h}$. (A) Western blotting was performed to determine the indicated protein levels of (B) MMP-9, (C) Akt, p-Akt, p-mTOR and mTOR. Densitometric measurements of protein analysis for the ratio of phosphorylated to total (D) Akt and (E) mTOR were also evaluated. Data are presented as the mean \pm standard deviation ( $\mathrm{n}=3$ ). ${ }^{\text {*P }}<0.05$ vs. control group. p-/phos-, phosphorylated; t-, total; Akt, protein kinase B; MMP-9, matrix metalloproteinase-9; mTOR, mammalian target of rapamycin; DMSO, dimethylsulfoxide.
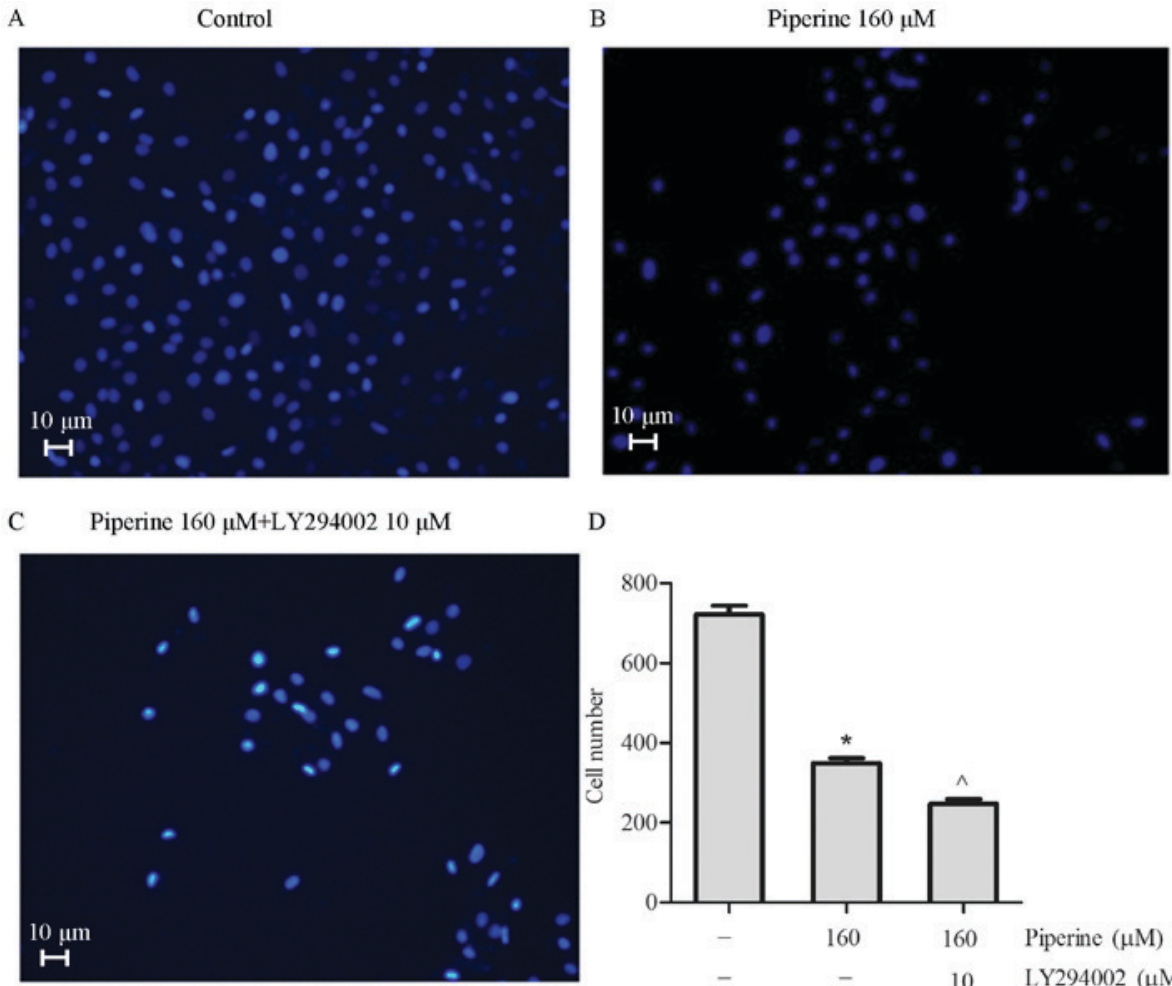

$\mathrm{D}$

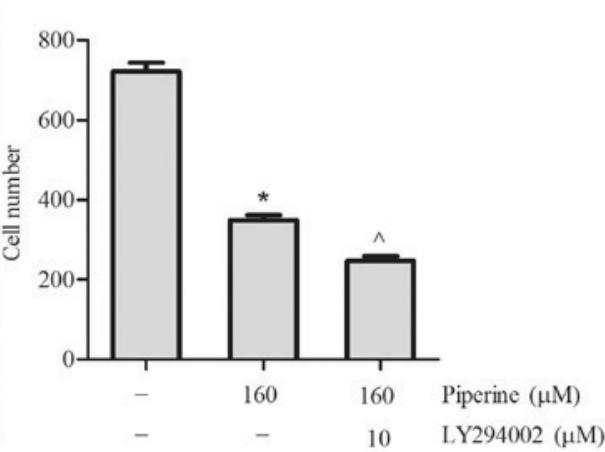

Figure 5. Piperine combined with LY294002 markedly represses cell migration in DU145 cells. The number of DU145 cells treated with (A) control,(B) piperine $(160 \mu \mathrm{M})$ and $(\mathrm{C})$ piperine $(160 \mu \mathrm{M})+\mathrm{LY} 294002(10 \mu \mathrm{m})$ that penetrated the membrane were calculated following $24 \mathrm{~h}$ (scale bars, $10 \mu \mathrm{m})$. (D) One representative experiment from three independently executed tests with similar consequences is presented. Data are presented as the mean \pm standard deviation $(\mathrm{n}=3$ ). ${ }^{*} \mathrm{P}<0.05$ vs. Control group; ${ }^{\wedge} \mathrm{P}<0.05$ vs. Piperine treatment group. 

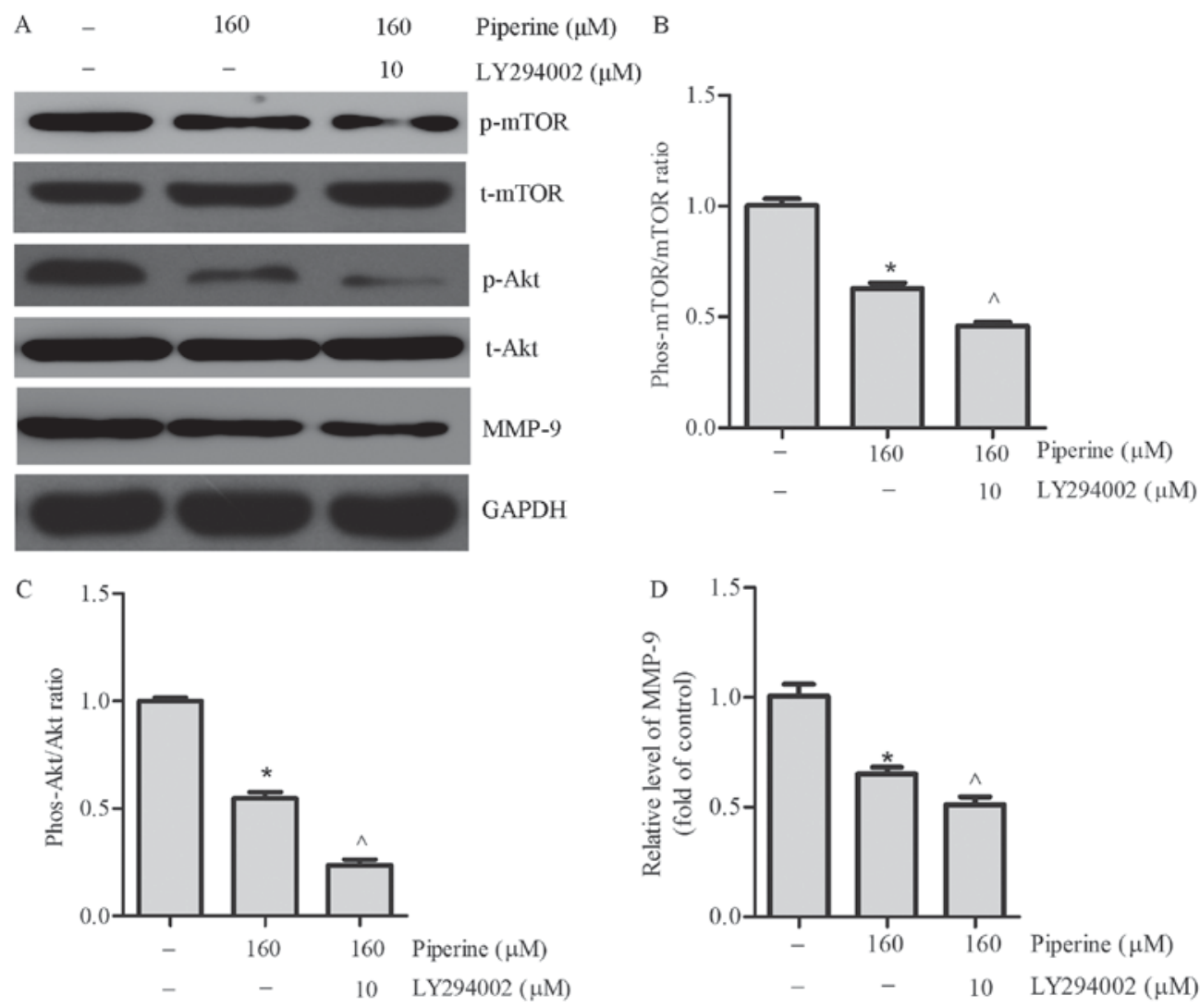

Figure 6. Piperine combined with LY294002 significantly decreases p-Akt, p-mTOR and MMP-9 protein levels in DU145 cells. Cells were treated with piperine $(160 \mu \mathrm{M})$ and piperine $(160 \mu \mathrm{M})+\mathrm{LY} 294002(10 \mu \mathrm{M})$ for $48 \mathrm{~h}$. (A) Western blot analysis was performed to evaluate the protein expression of (B) p-mTOR, (C) p-Akt and (D) MMP-9 in DU145 cells. Data are presented as the mean \pm standard deviation ( $\mathrm{n}=3$ ). ${ }^{*} \mathrm{P}<0.05$ vs. control group; ${ }^{\wedge} \mathrm{P}<0.05$ vs. Piperine treatment group. p-/phos-, phosphorylated; t-, total; Akt, protein kinase B; MMP-9, matrix metalloproteinase-9; mTOR, mammalian target of rapamycin.

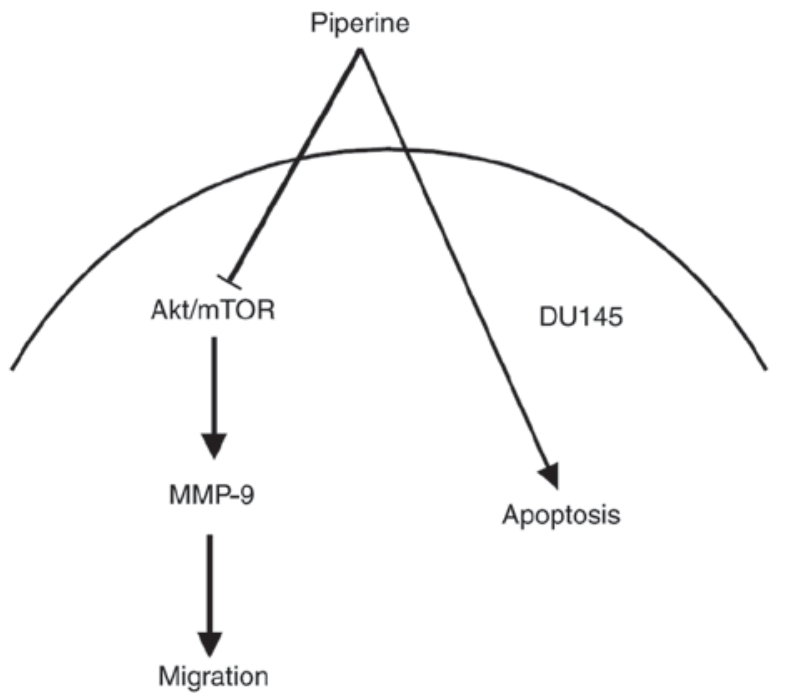

Figure 7. Piperine depresses the progression of migration by downregulating the Akt/mTOR/MMP-9 signaling pathway in DU145 cells. The piperine-induced downregulation of $\mathrm{Akt} / \mathrm{mTOR}$ signaling, was combined with the inhibition of MMP-9 expression and thus, cell migration. Akt, protein kinase B; MMP-9, matrix metalloproteinase-9; mTOR, mammalian target of rapamycin.

cells (LNCaP), and decreased the cell migration of LNCaP and PC-3 cells in Boyden chamber assay (22). Furthermore, our data revealed that piperine could significantly repress the proliferation and induce apoptosis of DU145 cells. Besides, our data also exhibited that the downregulation of MMP-9 expression resulted in inhibition of migration in DU145 cells. Accordingly, these findings implied that piperine acted a vital role in treatment of human PCa cells.

Numerous genetic changes occur during the process of carcinogenesis. Identifying vital proteins, such as PI3K, Akt, and ERK MAPK involved in these processes is crucial for comprehending carcinogenesis and creating new therapies (23-25). The PI3K/Akt signaling pathway is occupied in cell migration and invasion $(26,27)$. Recent researches indicated that the signaling pathway $\mathrm{PI} 3 \mathrm{~K} / \mathrm{Akt} / \mathrm{mTOR}$ is essential in the metastasis of PCa $(28,29)$. Besides, MMPs, a group of zinc-dependent endopeptidases, are involved in the degradation of the extracellular matrix under normal physiological conditions and during the metastatic process (30). MMP-9 is a vital effector molecule that boosts tumor cell invasion via type-IV collagen degradation-dependent extracellular matrix remodeling (31). In order to exam if piperine targets the PI3K/Akt/mTOR signaling-mediated cellular events in DU145 cells, the effect of piperine on these signaling molecules was explored by immunoblotting. In accordance with these reports $(9,32)$, we detected that piperine caused a decrease in cellular levels of Akt and mTOR. Through our work, a relation emerges between MMP-9 expression and levels of phosphorylated Akt and mTOR, which alters cell migration. The expression of phosphorylated Akt, phosphorylated mTOR, and MMP-9 were remarkable diminished 
in pretreatment with Akt inhibitor LY294002 group. Besides, inhibition of Akt activity also led to a decrease in migration, measured in a transwell migration assay. Taken together, our result suggested that piperine repressed the migration and the expression of MMP-9 via Akt/mTOR signaling pathway in DU145 cells partially.

We acknowledge that this study has some limitations. First, we just detected the effect of piperine in DU145 cells. Future studies should investigate the effect of piperine in other PCa cell lines. Second, our result suggested that piperine significantly reduced the expression of MMP-9 via Akt/mTOR signaling pathway in DU145 cells; however, more definitive target protein, such as EMT-related proteins including E-cadherin, TTF-1, are still needed. Similarly, there are several apoptosis-related proteins, and we studied only pro-apoptotic protein Bax and anti-apoptotic protein $\mathrm{Bcl}-2$, and did not directly assess other apoptosis-related proteins, which would be the subject of our future research. Finally, in vivo experiments using knock out mouse models are necessary to further validate the influence of piperine in $\mathrm{PCa}$.

In conclusion, our data reveal that piperine inhibits $\mathrm{PCa}$ cells migration via suppressing Akt/mTOR and downregulating MMP-9, and that the Akt/mTOR signaling seem to be the upstream regulators of MMP-9 protein (the schematic model is shown in Fig. 7). In brief, it is indicated that piperine represses metastasis through inhibiting the Akt/mTOR/MMP-9 signaling pathway in DU145 cells partially, and that it may be a potential anticancer drug candidate in future therapeutic medications in PCa patients.

\section{Acknowledgements}

Not applicable.

\section{Funding}

The present study was supported by the Science Fund of Northwest University (grant no. 2016023).

\section{Availability of data and materials}

The analyzed datasets generated during the study are available from the corresponding author on reasonable request.

\section{Authors' contributions}

YZ designed the study, and YZ and YY performed the experiments and analysis.

\section{Ethics approval and consent to participate}

Not applicable.

\section{Consent for publication}

Not applicable.

\section{Competing interests}

The authors declare that they have no competing interests.

\section{References}

1. Cooperberg MR and Chan JM: Epidemiology of prostate cancer. World J Urol 35: 849, 2017.

2. Shetty AV, Thirugnanam S, Dakshinamoorthy G, Samykutty A, Zheng G, Chen A, Bosland MC, Kajdacsy-Balla A and Gnanasekar M: 18 $\alpha$-glycyrrhetinic acid targets prostate cancer cells by down-regulating inflammation-related genes. Int $\mathrm{J}$ Oncol 39: 635-640, 2011.

3. Sharifi N, Gulley JL and Dahut WL: Androgen deprivation therapy for prostate cancer. JAMA 294: 238-244, 2005.

4. Pan H, Jansson KH, Beshiri ML, Yin J, Fang L, Agarwal S, Nguyen H, Corey E, Zhang Y, Liu J, et al: Gambogic acid inhibits thioredoxin activity and induces ROS-mediated cell death in castration-resistant prostate cancer. Oncotarget 8: 77181-77194, 2017.

5. Dias A, Kote-Jarai Z, Mikropoulos C and Eeles R: Prostate cancer germline variations and implications for screening and treatment. Cold Spring Harb Perspect Med: Nov 3, 2017 (Epub ahead of print)

6. Chen Z, Zheng Y, Ji G, Liu X, Li P, Cai L, Guo Y and Yang J: Accuracy of dynamic contrast-enhanced magnetic resonance imaging in the diagnosis of prostate cancer: Systematic review and meta-analysis. Oncotarget 8: 77975-77989, 2017.

7. Mittal R and Gupta RL: In vitro antioxidant activity of piperine. Methods Find Exp Clin Pharmacol 22: 271-274, 2000.

8. Pan H, Xu LH, Huang MY, Zha QB, Zhao GX, Hou XF, Shi ZJ, Lin QR, Ouyang DY and He XH: Piperine metabolically regulates peritoneal resident macrophages to potentiate their functions against bacterial infection. Oncotarget 6: 32468-32483, 2015.

9. Doucette CD, Greenshields AL, Liwski RS and Hoskin DW: Piperine blocks interleukin-2-driven cell cycle progression in CTLL-2 T lymphocytes by inhibiting multiple signal transduction pathways. Toxicol Lett 234: 1-12, 2015.

10. Sethiya NK, Shah P, Rajpara A, Nagar PA and Mishra SH: Antioxidant and hepatoprotective effects of mixed micellar lipid formulation of phyllanthin and piperine in carbon tetrachloride-induced liver injury in rodents. Food Funct 6: 3593-3603, 2015 .

11. Toyoda T, Shi L, Takasu S, Cho YM, Kiriyama Y, Nishikawa A, Ogawa K, Tatematsu M and Tsukamoto T: Anti-inflammatory effects of capsaicin and piperine on helicobacter pylori-induced chronic gastritis in mongolian gerbils. Helicobacter 21: 131-142, 2016.

12. Sharma S, Kalia NP, Suden P, Chauhan PS, Kumar M, Ram AB, Khajuria A, Bani S and Khan IA: Protective efficacy of piperine against mycobacterium tuberculosis. Tuberculosis (Edinb) 94: 389-396, 2014.

13. Greenshields AL, Doucette CD, Sutton KM, Madera L, Annan H, Yaffe PB, Knickle AF, Dong Z and Hoskin DW: Piperine inhibits the growth and motility of triple-negative breast cancer cells. Cancer Lett 357: 129-140, 2015.

14. Do MT, Kim HG, Choi JH, Khanal T, Park BH, Tran TP, Jeong TC and Jeong HG: Antitumor efficacy of piperine in the treatment of human HER2-overexpressing breast cancer cells. Food Chem 141: 2591-2599, 2013.

15. Zhang J, Sikka S, Siveen KS, Lee JH, Um JY, Kumar AP, Chinnathambi A, Alharbi SA, Basappa, Rangappa KS, et al: Cardamonin represses proliferation, invasion, and causes apoptosis through the modulation of signal transducer and activator of transcription 3 pathway in prostate cancer. Apoptosis 22: 158-168, 2017.

16. Kou B, Liu W, He W, Zhang Y, Zheng J, Yan Y, Zhang Y, Xu S and Wang $\mathrm{H}$ : Tetrandrine suppresses metastatic phenotype of prostate cancer cells by regulating Akt/mTOR/MMP-9 signaling pathway. Oncol Rep 35: 2880-2886, 2016.

17. Berrak O, Arisan ED, Obakan-Yerlikaya P, Coker-Gürkan A and Palavan-Unsal N: mTOR is a fine tuning molecule in CDK inhibitors-induced distinct cell death mechanisms via $\mathrm{PI} 3 \mathrm{~K} / \mathrm{AKT} / \mathrm{mTOR}$ signaling axis in prostate cancer cells. Apoptosis 21: 1158-1178, 2016.

18. Deepak V, Kruger MC, Joubert A and Coetzee M: Piperine alleviates osteoclast formation through the p38/c-Fos/NFATc1 signaling axis. Biofactors 41: 403-413, 2015.

19. Doucette CD, Hilchie AL, Liwski R and Hoskin DW: Piperine, a dietary phytochemical, inhibits angiogenesis. J Nutr Biochem 24: 231-239, 2013.

20. Fofaria NM, Kim SH and Srivastava SK: Piperine causes G1 phase cell cycle arrest and apoptosis in melanoma cells through checkpoint kinase-1 activation. PLoS One 9: e94298, 2014. 
21. Ouyang DY, Zeng LH, Pan H, Xu LH, Wang Y, Liu KP and $\mathrm{He} \mathrm{XH}$ : Piperine inhibits the proliferation of human prostate cancer cells via induction of cell cycle arrest and autophagy. Food Chem Toxicol 60: 424-430, 2013.

22. Samykutty A, Shetty AV, Dakshinamoorthy G, Bartik MM, Johnson GL, Webb B, Zheng G, Chen A, Kalyanasundaram R and Munirathinam G: Piperine, a bioactive component of pepper spice exerts therapeutic effects on androgen dependent and androgen independent prostate cancer cells. PLoS One 8: e65889, 2013.

23. Ai XL, Chi Q, Qiu Y, Li HY, Li DJ, Wang JX and Wang ZY: Gap junction protein connexin43 deregulation contributes to bladder carcinogenesis via targeting MAPK pathway. Mol Cell Biochem 428: 109-118, 2017.

24. He Q, Ren X, Chen J, Li Y, Tang X, Wen X, Yang X, Zhang J, Wang Y, Ma J and Liu N: miR-16 targets fibroblast growth factor 2 to inhibit NPC cell proliferation and invasion via PI3K/AKT and MAPK signaling pathways. Oncotarget 7: 3047-3058, 2016.

25. Zhang D, Sun G, Zhang H, Tian J and Li Y: Long non-coding RNA ANRIL indicates a poor prognosis of cervical cancer and promotes carcinogenesis via PI3K/Akt pathways. Biomed Pharmacother 85: 511-516, 2017.

26. Li C, Wang C, Xing Y, Zhen J and Ai Z: CD133 promotes gallbladder carcinoma cell migration through activating Akt phosphorylation. Oncotarget 7: 17751-17759, 2016.

27. Selvaraj N, Budka JA, Ferris MW, Jerde TJ and Hollenhorst PC: Prostate cancer ETS rearrangements switch a cell migration gene expression program from RAS/ERK to PI3K/AKT regulation. Mol Cancer 13: 61, 2014.
28. Marques RB, Aghai A, de Ridder CMA, Stuurman D, Hoeben S, Boer A, Ellston RP, Barry ST, Davies BR, Trapman J and van Weerden WM: High efficacy of combination therapy using PI3K/AKT inhibitors with androgen deprivation in prostate cancer preclinical models. Eur Urol 67: 1177-1185, 2015.

29. Chen H, Zhou L, Wu X, Li R, Wen J, Sha J and Wen X: The PI3K/AKT pathway in the pathogenesis of prostate cancer. Front Biosci (Landmark Ed) 21: 1084-1091, 2016.

30. Koutroulis I, Zarros A and Theocharis S: The role of matrix metalloproteinases in the pathophysiology and progression of human nervous system malignancies: A chance for the development of targeted therapeutic approaches? Expert Opin Ther Targets 12: 1577-1586, 2008.

31. Khan MN, Choi JS, Lee MC, Kim E, Nam TJ, Fujii H and Hong YK: Anti-inflammatory activities of methanol extracts from various seaweed species. J Environ Biol 29: 465-469, 2008.

32. Yaffe PB, Power Coombs MR, Doucette CD, Walsh M and Hoskin DW: Piperine, an alkaloid from black pepper, inhibits growth of human colon cancer cells via G1 arrest and apoptosis triggered by endoplasmic reticulum stress. Mol Carcinog 54: 1070-1085, 2015

c) (7) $\odot$ This work is licensed under a Creative Commons

EY NO ND Attribution-NonCommercial-NoDerivatives 4.0 International (CC BY-NC-ND 4.0) License. 